\title{
Concepções de Ciências das professoras que atuam na Educação Infantil
}

\author{
Sciences conceptions of teachers acting in Childhood Education \\ Concepciones Científicas de maestros que actúan en Educación \\ Infantil
}

Rosanara Bourscheid ${ }^{1}$; Judite Scherer Wenzel ${ }^{2}$

\section{RESUMO}

O presente artigo contempla um estudo sobre algumas concepções que foram indiciadas por sete professoras que atuam na Educação Infantil ao responderem um questionário com uma questão aberta que se referia sobre como elas percebem o ensino de Ciências na Educação Infantil. Os dados coletados foram analisados por meio da Análise Textual Discursiva (MORAES; GALIAZZI, 2006) que possibilitou uma impregnação com o texto e, utilizamos categorias a priori já apontadas na literatura sendo elas: Instituição, Conhecimento e Método. Foi possível indiciar com mais ênfase uma compreensão de Ciência como Método, seguida pela do Conhecimento e, a que teve menos indícios foi a de Instituição. Os resultados indicam a necessidade de um contínuo processo de formação continuada para ampliar e qualificar as compreensões sobre o que é Ciências para assim qualificar o seu ensino e a prática pedagógica.

Palavras-chave: Formação continuada; Natureza da Ciência; Desenvolvimento Infantil.

\begin{abstract}
This article contemplates a study on some conceptions that were indicted by seven teachers who work in Early Childhood Education when they answered a questionnaire with an open question that referred to how they perceive the teaching of Science in Early Childhood Education. The collected data were analyzed through Discursive Textual Analysis (MORAES; GALIAZZI, 2006) which allowed an impregnation with the text and we used a priori categories already pointed out in the literature, namely: Institution, Knowledge and Method. It was possible to point out with more emphasis an understanding of Science as a Method, followed by Knowledge, and the one that had the least evidence was that of Institution. The results indicate the need for a continuous process of continuing education to expand and qualify the understanding of what Science is, in order to qualify its teaching and pedagogical practice.
\end{abstract}

Keywords: Continuing education; Nature of Science; Child development.

\section{RESUMEN}

Este artículo contempla un estudio sobre algunas concepciones que fueron imputadas por siete docentes que laboran en Educación Infantil cuando respondieron un cuestionario con una pregunta abierta que se refería a cómo perciben la enseñanza de las Ciencias en Educación Infantil. Los datos recolectados se analizaron mediante Análisis Textual Discursivo (MORAES; GALIAZZI, 2006) que permitió una impregnación con el texto y se utilizaron categorías a priori ya mencionadas en la literatura, a saber: Institución, Conocimiento y Método. Se pudo señalar con mayor énfasis una comprensión de la Ciencia como Método, seguida del Conocimiento, y

\footnotetext{
${ }^{1}$ Mestranda em Ensino de Ciências - Universidade Federal Fronteira Sul (UFFS), Cerro Largo/RS - Brasil. E-mail: rosanarab@gmail.com

${ }^{2}$ Doutora em Educação nas Ciências e Professora Adjunta da Universidade Federal da Fronteira Sul, Cerro Largo/RS - Brasil. E-mail: juditescherer@uffs.edu.br
} 
la que menos evidencias tuvo fue la de Institución. Los resultados indican la necesidad de un proceso continuo de formación continua para ampliar y calificar la comprensión de lo que es la Ciencia para calificar su práctica docente y pedagógica.

Palabras clave: Educación continua; Naturaleza de la ciencia; Desarrollo infantil.

\section{INTRODUÇÃO}

Ensinar Ciências na Educação Infantil é um desafio para os professores que atuam em tal contexto uma vez que eles necessitam estar em constante formação a fim de compreenderem sobre o que e como Ensinar Ciências para as crianças. A criança tem o direito de aprender por meio das interações e brincadeiras pelas quais "[...] constrói sua identidade pessoal e coletiva, brinca, imagina, fantasia, deseja, aprende, observa, experimenta, narra, questiona e constrói sentidos sobre a natureza e a sociedade, produzindo cultura" (DCNEI, 2010, p. 12).

Para tanto, o professor necessita organizar os ambientes e propor situações de aprendizagem ricas em exploração, observação, que instiguem a curiosidade das crianças por meio de perguntas, hipóteses e desafios a partir do cotidiano, oportunizando a compreensão do mundo em que está inserida e assim, contemplar o que aponta as Diretrizes Curriculares Nacionais para a Educação Infantil (DCNEI, 2010) ao mencionar que na Educação Infantil é importante trabalhar com um,

conjunto de práticas que buscam articular as experiências e os saberes das crianças com os conhecimentos que fazem parte do patrimônio cultural, artístico, ambiental, científico e tecnológico, de modo a promover o desenvolvimento integral de crianças de 0 a 5 anos de idade (DCNEI, 2010, p. 12).

Compreendemos que o desenvolvimento integral da criança contempla o Ensino de Ciências com isso, apontamos que qualificar os modos de ensinar Ciências é uma necessidade, tendo em vista a constante evolução do conhecimento científico que interfere e modifica a vida das pessoas, seja no cotidiano da vida pessoal, social, profissional ou cultural. Machado (2007) destaca que a concepção de Ciência que o professor traz é muito importante pois é na escola que se aprende a formar opinião sobre o mundo em que se vive. Assim, "[...] as aulas de ciências passam a ser vistas como momentos nos quais professores e alunos podem interagir na busca da compreensão e interpretação dos fenômenos" (MACHADO, 2007, p. 23).

Considerando a Educação Infantil e, partindo da compreensão da necessidade de qualificar a inserção do Ensino de Ciências, apontamos como importante que o professor que atua em tal contexto tenha oportunidades de dialogar e de refletir com os pares sobre a importância de ensinar Ciências na Educação Infantil, pois a escola é o lugar de construir aprendizagens. Nas palavras de Machado (2007, p. 21) "[...] é de grande relevância estudar a ciência na escola" e o professor precisa planejar situações de aprendizagens que contemplem aspectos científicos, pautadas num processo de construção do conhecimento a partir da realidade das crianças.

Para tanto é necessário possibilitar espaços formativos que auxiliem na compreensão da natureza da Ciência numa perspectiva epistemológica e histórica. O professor para ensinar Ciências precisa conhecer e construir significados sobre os aspectos do conhecimento científico. Praia, Cachapuz e Gil-Pérez (2002, p. 140) indicam a importância de "[...] o professor não assente o seu saber, sobretudo na informação, mas que possa também desenvolver conhecimentos e saberes no modo como se investiga como se faz ciência". 
É fundamental que os professores compreendam que o Ensino de Ciências precisa ser trabalhado com a participação da criança, por meio da problematização, da construção de hipóteses instigando a criança a perguntar, a observar e a compreender alguns termos da Ciência.

O ensino de ciências na educação infantil tem grande importância ao promover a exploração e o conhecimento do mundo real, [...] oportuniza desenvolvimento de habilidades de raciocínio, imaginação e criação junto às crianças pequenas (UJIIE, 2020, p.19).

Esse também é um desafio proposto nos documentos oficiais que norteiam o currículo. A BNCC (BRASIL, 2017) como objetivos de aprendizagem e desenvolvimento nos campos de experiências aponta para um Ensino de Ciências numa perspectiva contextualizadora e problematizadora, que estimule a participação da criança. De modo especial destacamos o campo de experiência espaços, tempos, quantidades, relações e transformações como mais próximo ao Ensino de Ciências por apresentar "[...] tempos (dia e noite; hoje, ontem e amanhã [...] mundo físico, seu próprio corpo, os fenômenos atmosféricos, os animais, as plantas, as transformações da natureza, os diferentes tipos de materiais e as possibilidades de sua manipulação [...]" (BRASIL, 2017, p. 42-43).

Compreendemos que a concepção de Ciência do professor interfere diretamente no seu planejamento de ensino e nas ações que são realizadas em sala de aula. Para Harres (1999, p. 201) "[...] o conhecimento dos professores pode estar composto de múltiplas relações entre muitos elementos como personalidade, experiências prévias, condições contextuais, valores, etc. que influem na sua conduta".

Nesse aspecto é importante considerar as concepções cientificas dos professores, pois tal conhecimento estará refletido nas suas intervenções pedagógicas e colabora para "[...] favorecer um trabalho de mudança didática que conduza os professores (em formação ou em atividade), a partir das suas próprias concepções, a ampliarem seus recursos e modificarem suas perspectivas" (CARVALHO, 2011, p. 31).

Compreendemos que para qualificar o Ensino de Ciências com crianças é necessário um espaço de formação inicial e continuada que possibilite aos professores a compreensão da Natureza da Ciência, da sua construção humana e histórica, de acordo com Hai et al. (2020, p. 104) "o professor de educação infantil deve receber um suporte científico suficiente, que o permita ser capaz de dominar tanto os conteúdos científicos, como os meios que levam ao estabelecimento de novos conceitos".

O professor é o mediador do ensino e aprendizagem, precisa ouvir e observar como as crianças brincam para assim oportunizar o desenvolvimento por meio de situações de ensino que promovam o cuidado, qualifiquem as interações e estimulem as brincadeiras. E, em todo esse processo, é importante considerar as diversas linguagens e, em seu planejamento contemplar os conceitos científicos.

Assim, a intervenção intencional do professor é de grande importância, porque é ele que organiza espaços, tempos, relações pessoais e situações propícias às atividades infantis, com a finalidade de fazer com que as crianças construam conhecimentos de forma coletiva, nesse ambiente educacional (FORETTI, 2028, p. 47).

Acreditamos que ensinar Ciências na Educação Infantil é fundamental pois é nesta idade e, é neste espaço da instituição escolar, que as crianças têm a oportunidade de iniciar a sua compreensão na Ciência por meio de interações com o outro, pela vivência social e cultural. A escola tem um papel importante em trabalhar os conhecimentos científicos desde a Educação Infantil, para Hai et al. (2020, 
p. 33) "[...] educar cientificamente as crianças por meio do Ensino de Ciências é permitir que elas se apropriem dessa riqueza produzida pelo homem".

É importante para Ensinar Ciências, conforme aponta Moura (2014, p. 37) "[...] compreender como o homem constrói o conhecimento científico em cada contexto e em cada época, tendo como base suas concepções filosóficas, ideológicas e metodológicas", ou seja, esses aspectos que contemplam a natureza da Ciência são importantes de serem dialogados na formação de professores uma vez que eles são os mediadores do processo de ensino e aprendizagem.

Acreditamos na importância de o professor, que atua na Educação Infantil vivenciar espaços formativos que potencializem a sua compreensão acerca da Ciência a fim de oportunizar as crianças situações desafiadoras que as iniciam na construção do conhecimento científico para "[...] promover experiências nas quais as crianças possam fazer observações, manipular objetos, investigar e explorar seu entorno, levantar hipóteses" (BRASIL, 2017, p. 43).

Considerando a importância da compreensão do professor sobre Ciência buscamos indícios dos modos de como os professores que atuam na Educação Infantil compreendem Ciência. Para tanto realizamos, com um grupo de professoras ${ }^{3}$, um questionário com algumas questões abertas. 0 presente artigo se refere as repostas dadas para a pergunta: como você percebe o Ensino de Ciências na Educação Infantil? Acreditamos que ao escrever sobre o modo de ensino de Ciências a professora indica também a sua compreensão acerca da Ciência. Como aliado no processo analítico trabalhamos com categorias a priori, já apontadas por Machado (2007), a saber: Instituição, Método e Conhecimento. Segue um diálogo da metodologia de análise adotada.

\section{METOdOLOGIA DE ANÁlise, CONTEXTO E SUJEITOS DA PESQUISA}

O estudo caracteriza-se como pesquisa qualitativa (LÜDKE; ANDRÉ, 1986, p.11) "[...] a pesquisa qualitativa tem o ambiente natural como sua fonte de dados e o pesquisador como principal instrumento". Os dados foram coletados e construídos por meio das respostas de sete professoras participantes de um grupo de formação continuada para a pergunta: Como você percebe o Ensino de Ciências na Educação Infantil? A qual integrava um questionário semi-estruturado mais amplo que visava conhecer o perfil das professoras.

Para este estudo utilizamos o questionário semi-estruturado, por ser um instrumento da pesquisa qualitativa que oportuniza aos participantes responder de forma direcionada e aberta as suas compreensões sobre a temática de pesquisa do pesquisador, "[...] não há a imposição de uma ordem rígida de questões, o entrevistado discorre sobre o tema proposto com base nas informações que ele detém e que no fundo são a verdadeira razão da entrevista" (LÜDKE; ANDRÉ, 1986, p.39).

As referidas professoras atuam numa escola da Rede Municipal da Região Noroeste do Estado do Rio Grande do Sul e participam de um grupo de formação continuada desde agosto de 2020. Os encontros de formação apresentaram como foco dialogar sobre o Ensino de Ciências na Educação Infantil e, para iniciar o diálogo as professoras foram convidadas, seguindo os preceitos éticos da pesquisa a

\footnotetext{
3 Professoras que atuam na Educação Infantil participantes de um grupo de formação que foi iniciado em setembro do ano de 2020, cuja finalidade foi promover um espaço de formação por meio da Investigação Formação Ação com professores que atuam na Educação Infantil como modo de qualificar a compreensão acerca do Ensino de Ciências.
} 
responderem o questionário semi-estruturado que visava um maior conhecimento das professoras. Delas, uma é formada em Matemática, uma em Artes Plásticas e cinco tem formação em Pedagogia, e atuam na Educação Infantil num período de cinco a onze anos. Visando preservar a identidade das professoras, no decorrer dos resultados utilizamos a sigla $\mathrm{P}$ para indicar Professora, e a numeração de 01 a 07, para diferenciar as professoras.

Para análise das respostas seguimos os preceitos da Análise Textual Discursiva (ATD) de Moraes e Galiazzi (2011, p. 07) que [...] "corresponde a uma metodologia de análise de dados e informações de natureza qualitativa com a finalidade de produzir novas compreensões sobre os fenômenos e discursos". Na mesma dinâmica os referidos autores evidenciam a importância do envolvimento do pesquisador que, por sua vez "[...] precisa assumir-se intérprete e autor" (MORAES, GALIAZZI 2011, p. 10).

A ATD de acordo com Moraes e Galiazzi (2006, p. 122) "constitui processo recursivo continuado para uma maior qualificação do que foi produzido". Por meio da ATD é importante considerar a linguagem como central, além de algumas etapas para a realização do estudo e análise como: desconstrução, comunicação e emergência por meio dos quais buscamos compreender e construir sentidos a partir dos excertos das respostas e construir significado das compreensões das professoras, os quais formam o conjunto de textos que compõe o corpus da pesquisa.

No processo inicial de desconstrução, de acordo com Moraes e Galiazzi (2006, p.123), ocorre a "[...] unitarização, a fragmentação, codificação e atribuição de títulos a unidades elementares de sentido construídas a partir de uma leitura e impregnação intensa com o material da análise".

Os dados foram pincelados das respostas atribuídas pelas professoras para a questão que as desafiou a responder sobre como percebem o ensino de Ciências na Educação Infantil. Apesar de não serem questionadas de forma explícita sobre a compreensão do que é Ciências, as respostas atribuídas pelas professoras possibilitaram identificar indícios de aproximações acerca da sua compreensão de Ciência. Segue alguns recortes da ATD.

O Ensino de Ciências é voltado para a ampliação das experiências das crianças. $\left(\mathrm{P}_{1}\right)$.

A Ciência faz com que a criança conheça mais sobre si, e tudo o que está ao seu redor. $\left(\mathrm{P}_{2}\right)$.

Ensino de Ciências instiga a curiosidade ao conhecimento, propicia a interação com diferentes materiais. $\left(\mathrm{P}_{6}\right)$.

Para Chalmers (1993) indica que essas compreensões constituem os questionamentos a respeito do que as professoras pensam sobre como e o que é ensinado em Ciências, por meio dos questionamentos sobre O quê? Como? E Por Quê? Conforme Machado (2007) essas questões orientam a compreensão das professoras no que se refere às dimensões da Ciência como Instituição, Método e Conhecimento. Compreendemos que as concepções de Ciências perpassam e são constitutivas das práticas de ensino das professoras.

No processo analítico fizemos uso de categorias a priori já apontadas por Machado (2007), a qual teve como base teórica (BERNAL, 1997), que classifica a Ciência nas dimensões: Instituição, Método e Conhecimento. Na dimensão da ciência como Instituição conforme Machado (2007, p. 50) "a ciência se manifesta pelo seu papel na sociedade mediante uma organização que lhe confere um caráter institucional. [...]. Essas dimensões da ciência são manifestações de um todo complexo que 
caracteriza a ciência contemporânea". Já a compreensão da ciência como Método "não é algo fixo, e considera as relações de caráter social, e da ciência [...] observação e experimentação, classificação e mediação, aparelho científico, leis, hipóteses e teorias, a linguagem da ciência, a estratégia da ciência, ciência e arte e cientista e engenheiro" (MACHADO, p. 46 e 47).

Já a Ciência como Conhecimento "é um descobrimento constante de fatos, leis e teorias novas que critica e com frequência destrói muito do construído [...] efetua reparos constantemente, mas que nunca se deixa de utilizar" (MACHADO, 2007, p. 47 e p. 49). Considerando essas concepções de Ciência como Instituição, Método e Conhecimento buscamos estudar, compreender por meio a ATD como tais compreensões se mostram nas respostas das professoras, seguem os resultados construídos.

\section{RESULTADOS E DISCUSSÃO}

A partir das compreensões de Ciências indicadas por Machado (2007) realizamos a interpretação e classificação das respostas descritas pelas professoras, obtivemos como resultado o indicativo apresentado no quadro 01 que segue.

Quadro 01: Indícios das categorias

\begin{tabular}{|c|c|c|c|}
\hline Professora & $\begin{array}{c}\text { Ciência como } \\
\text { Instituição }\end{array}$ & $\begin{array}{c}\text { Ciência como } \\
\text { Método }\end{array}$ & $\begin{array}{c}\text { Ciência como } \\
\text { Conhecimento }\end{array}$ \\
\hline$P_{1}$ & & $X$ & $X$ \\
\hline$P_{2}$ & & $X$ & $X$ \\
\hline$P_{3}$ & & $X$ & $X$ \\
\hline$P_{4}$ & & $X$ & $X$ \\
\hline$P_{5}$ & $X$ & $X$ & $X$ \\
\hline$P_{6}$ & $X$ & $X$ & 05 indícios \\
\hline$P_{7}$ & $X$ & 06 indícios & \\
\hline Total & 03 indícios & & \\
\hline
\end{tabular}

Fonte: BOURSCHEID; WENZEL 2020.

No processo de análise foi possível evidenciar um maior número de indícios apontando para uma visão de Ciência mais próxima de uma compreensão de Método, seguida pela do conhecimento científico e, a que teve menos indícios foi a de Instituição. Algumas professoras indicaram na resposta mais de uma compreensão, apenas $\mathrm{P}_{2}$ e $\mathrm{P}_{3}$ apresentaram uma única compreensão. Retomamos alguns critérios referentes às dimensões da Ciência como: Instituição, Método e Conhecimento já apresentados por Machado (2007, p. 71).

A dimensão Conhecimento responde à pergunta o quê? Ela se expressa por palavras ou ideias referentes ao conteúdo, objeto de estudo e atributos do conhecimento científico. Por exemplo, no esquema relacional, a relação ciência - natureza pode ser interpretada como uma expressão da dimensão Conhecimento uma vez que a palavra natureza refere-se a um objeto de estudo da ciência, de onde surge o conhecimento científico. A dimensão Método responde à pergunta como? Ela se expressa por palavras ou ideias referentes aos procedimentos para a construção do conhecimento científico. Por exemplo, no esquema relacional, a relação ciência - experimentação pode ser interpretada como uma expressão da dimensão Método uma vez que a 
palavra experimentação refere-se ao modo como o conhecimento científico é construído. A dimensão Instituição responde às perguntas por quê? para quê? quem? e para quem? Elas se expressam por palavras ou ideias referentes às relações da ciência com a sociedade, aos aspectos sociais da ciência. Por exemplo, no esquema relacional, a relação ciência - economia pode ser interpretada como uma expressão da dimensão Instituição uma vez que a palavra economia refere-se a uma relação da ciência com a sociedade seja mediante uma ação da ciência na economia como uma ação da economia na ciência. (MACHADO, 2007, p. 71)

A Ciência como Método estava presente, conforme já apontou o quadro 01, nas respostas da maioria das participantes da pesquisa. Para Machado (2007, p. 73) tal entendimento retrata relações que auxiliam na produção do conhecimento científico, como observação - curiosidade - experimento, segundo a autora "[...] a ciência está relacionada com a curiosidade que leva ao experimento e à observação". E isso foi retratado nas respostas de seis professoras, conforme segue:

Através da ciência, a criança interpreta, descobre e constrói "teorias", facilitando a compreensão dos fatos do cotidiano e a resolução de problemas. $\left(\mathrm{P}_{1}\right)$.

Muito importante, porque desenvolve e estimula a curiosidade, a investigação, a pesquisa, o questionamento e muito mais. $\left(\mathrm{P}_{3}\right)$.

Percebo ele bem presente quando propomos atividades práticas que desenvolvem os sentidos e a coordenação motora. $\left(\mathrm{P}_{4}\right)$.

Explorar a curiosidade da criança, compreender fatos do cotidiano, resolver problemas práticos. $\left(\mathrm{P}_{5}\right)$.

A observação e o registro e a elaboração de explicações, assim explorando o mundo no seu entorno. $\left(\mathrm{P}_{6}\right)$.

Em tais excertos as professoras retratam a importância do Ensino de Ciências na Educação Infantil relacionando a sua compreensão como modo de oportunizar às crianças tanto a compreensão dos fatos do cotidiano, bem como, o desenvolvimento da curiosidade, da observação, do saber interpretar, da descoberta, da resolução de problemas.

[...] A resolução dos problemas que a prática pedagógica coloca, exige o uso de alguns referenciais que permitam interrogá-la, ao mesmo tempo em que proporcionam os parâmetros para as decisões que devem ser tomadas [...] os docentes, independentemente do nível em que trabalham, são profissionais que devem diagnosticar o contexto de trabalho, tomar decisões, atuar e avaliar a pertinência das atuações, a fim de reconduzi-las no sentido adequado (ZABALA, 1998, p. 10).

Assim, é importante a compreensão de que a educação tem um papel importante em instigar e incentivar a criança, contemplando uma construção do conhecimento complexa e contextualizada, por meio de práticas que contemplem a escuta pedagógica para oportunizar o desenvolvimento das diferentes linguagens, as quais se mostram fundamentais para o desenvolvimento infantil, "possibilitando a exploração do mundo por meio da manipulação objetal, inicia-se o processo de constituição do pensamento teórico e a utilização da linguagem de forma mais elaborada" (HAI, et al., 2020, p. 53). Esse processo de comunicação pelo uso da linguagem é importante para a criança expressar ao outro as informações e conhecimentos sobre si e sobre o seu cotidiano.

Tais posicionamentos indicam que o Ensino de Ciências é importante para desenvolver nas crianças a capacidade investigativa, pelo manuseio de objetos, pelo uso da observação e acompanhamento de fenômenos e pelo estímulo à criatividade. Tais aspectos, na perspectiva histórico-cultural, são 
considerados especificamente humanos e precisam ser desenvolvidos desde o "[...] início da infância, as atividades relacionadas com a ciência, com ricas experiências verbais e não verbais, auxiliarão a formação de fecundos reservatórios de materiais, que pouco a pouco, vão se transformando em conceitos mais ricos e elaborados" (ARCE; SILVA; VAROTTO; 2011, p.63).

O Conhecimento teórico das professoras sobre a importância do Ensino de Ciências é necessário para oportunizar experiências de aprendizagem para as crianças. As atividades práticas apontadas nos excertos, são fundamentais para que a criança vivencie situações de aprendizagem para compreender e construir o conhecimento científico por meio da participação interativa, questionando e elaborando hipóteses, e assim, vai sendo desenvolvido o método da construção do conhecimento científico, de o professor saber organizar o espaço educacional e as atividades educativas, pois é o professor "[...] quem concebe e coordena ambientes educativos e situações de aprendizagem" (FIORETTI, 2018, p.36).

Assim também destacamos, de acordo com Machado (2007, p. 50) que "o método não é único ele se encontra em um processo contínuo de desenvolvimento". E isso, precisa estar presente no Ensino de Ciência trazendo o contexto cultural, social em que a criança está inserida, conforme aponta a professora P7, "Trabalhar experiências de vida. Valorizar o cotidiano em que vivem. Buscar conhecimento através da curiosidade do mundo em que vivem". Ao considerar a categoria Conhecimento é importante destacar que ela indicia o que ensinar, e assim, foi possível pincelar algumas respostas das professoras, como:

Ciências é voltado para a ampliação das experiências das crianças e construção de conhecimentos $\left(\mathrm{P}_{1}\right)$.

[...] Através dele [conhecimento científico] a criança aprende mais sobre o eu, natureza e as curiosidades dela $\left(\mathrm{P}_{2}\right)$.

[...] o que se ensina? Trabalhamos o Ensino de Ciências [...]. Exemplo: órgãos dos sentidos, higiene, água, lixo $\left(\mathrm{P}_{5}\right)$.

Essa construção do conhecimento é parte integrante do processo de desenvolvimento dos conceitos científicos, o qual, [...] "na idade escolar é, antes de tudo, uma questão prática de imensa importância - talvez até primordial do ponto de vista das tarefas que a escola tem diante de si quando inicia a criança no sistema de conceitos científicos" (VIGOTSKI, 2009, p.241).

A visão e o conhecimento de cada uma das professoras sobre a Ciência são importantes para oportunizar situações desafiadoras na construção dos conceitos científicos, "Acredito ser fundamental, pois a ciência está relacionada em tudo o que nos rodeia, e quanto mais cedo isso for trabalhado, desenvolvido logo a criança aprende novas concepções" $\left(\mathrm{P}_{4}\right)$. E, ainda, "faz com que a criança conheça mais sobre si, e tudo o que está ao seu redor" $\left(\mathrm{P}_{2}\right)$. Para Machado (2007, p. 49) "através dos conhecimentos adquiridos através da ciência, podemos refletir sobre o mundo em que vivemos de formas diferentes". Consideramos que o conhecimento articulado às vivências no Ensino de Ciências é importante desde a Educação Infantil, para oportunizar às crianças os conhecimentos de forma crítica e criativa.

O ensino de ciências é ponte para a ação interdisciplinar, mola propulsora para o questionamento, para a busca e para pesquisa. A criança da educação infantil para construir conhecimentos científicos precisa atuar sobre o concreto, perguntar, tatear, ver com as mãos, ler o mundo, olhar imagens, criar relações, testar hipóteses, agir, pensar, refletir, de modo reestruturar o conhecimento e criar sua aprendizagem. (UJIIE, 2020, p. 41). 
Ao aproximar o diálogo com a categoria Instituição, apontamos que a escola é o lugar de desenvolver aprendizagens com relação as curiosidades da criança sobre os fenômenos naturais, seu corpo, fenômenos atmosféricos, animais, plantas. Para Machado (2007, p. 50) "a ciência se manifesta pelo seu papel na sociedade mediante uma organização que lhe confere um caráter institucional". A instituição escolar é o espaço social que cria oportunidades para que a criança amplie seus conhecimentos do mundo físico, natural e sociocultural para construir os conceitos científicos relacionados ao cotidiano.

Quando uma criança é exposta a um novo conceito, seu desenvolvimento está apenas começando, no início ele é um tipo de generalização elementar, que vai sendo substituído por generalizações cada vez mais elevadas, à medida que a criança desenvolve (VIGOTSKI, 1989, p. 246).

Observamos nas respostas das professoras alguns aspectos sobre a Concepção de Ciência como Instituição, nos quais foi possível identificar que os conceitos trabalhados precisam estar articulados com os aspectos sociais, com a sociedade e a tecnologia.

De acordo com Machado (2007, p. 136) "os professores sabem que é preciso ensinar ciências, mas o que é a ciência e como levar esse questionamento para a sala de aula é que é a questão" indicando a necessidade de reflexão no processo de formação dos professores. Nesse sentido, a forma de como se ensina na escola é um aspecto importante para instigar o gosto e a curiosidade das crianças na construção dos conhecimentos científicos desenvolvendo o encantamento pela ciência.

Nesse aspecto $\mathrm{P}_{6}$ indica em sua resposta que se ensina Ciências para "possibilitar uma formação $e$ desenvolvimento integral, tornando a criança mais pensante, ativa, questionadora (um adulto crítico e mais atuante na sociedade em que vive) e que busca conhecer tudo o que está ao seu redor". Assim, a concepção sobre o Ensino de Ciências da professora é importante para inserir a criança na cultura científica. As respostas das professoras dão indícios de que elas contemplam em suas práticas o Ensino de Ciências e isso é muito importante, pois reconhecer esse conhecimento como importante desde a Educação Infantil é fundamental.

Porém, para qualificar esse processo é necessário oportunizar espaços de diálogo sobre as questões epistemológicas da ciência de "[...] uma ciência, em algum estágio de seu desenvolvimento, envolverá um conjunto de técnicas para articular, aplicar e testar as teorias das quais é formada" (CHALMERS, 1993, p.159), para que as professoras ampliem seus conhecimentos sobre os aspectos que fazem parte do processo científico, compreendendo o Ensino de ciências de forma crítica e reflexiva. 0 estudo nessa perspectiva colabora para que as professoras compreendam a ciência como conhecimento em constante transformação, como construção humana e histórica sendo importante para a sociedade e para vida de cada sujeito.

\section{CONCLUSÃO}

O referido estudo sobre a questão "como você percebe o ensino de Ciências na Educação Infantil?" possibilitou a compreensão de que as professoras apresentam concepções de ciências de acordo com os conhecimentos construídos em suas formações, e de suas vivências culturais. A partir da análise observamos as concepções tendo como referência as categorias definidas a priori como método e 
conhecimento, as quais destacamos maior números de excertos, uma vez que em suas respostas, as professoras indicaram como e o que é trabalhado no Ensino de Ciências.

Ainda, a realização da pesquisa possibilitou compreensões da categoria instituição que se refere ao por que ensinar Ciências no espaço da Educação Infantil. De acordo com P5 o Ensino de Ciências "Contribui para a formação da cidadania [...]". Assim, as professoras reconhecem a importância da Ciência para a constituição da criança, de forma participativa e crítica, bem como o seu compromisso social para a sociedade.

O resultado da análise indicou a importância do diálogo formativo sobre o Ensino de Ciências em tal etapa, numa perspectiva contextualizada por meio da problematização, que estimule a participação da criança. Ainda, apontamos a importância de oportunizar espaços de formação acerca da Ciência e do seu ensino a fim de qualificar o ensino e aprendizagem sobre as questões científicas desde a Educação Infantil.

Considerando que, de acordo com a BNCC, o currículo da Educação Infantil relacionado a Ciência perpassa os objetivos de aprendizagem e desenvolvimento de modo mais especifico no campo de experiência espaços, tempos, quantidades, relações e transformações com o seguinte destaque "[...] promover experiências nas quais as crianças possam fazer observações, manipular objetos, investigar e explorar seu entorno, levantar hipóteses" (BRASIL, 2017, p. 43). Neste aspecto reafirmamos que o conhecimento do professor é necessário para promover a construção do conhecimento da criança, bem como para inseri-la na cultura científica.

Nesse sentido, consideramos importante o estudo a partir da epistemologia da ciência, para que as professoras compreendam como é o processo de construção do conhecimento científico, uma vez que a ação pedagógica de cada professora está relacionada com as suas compreensões de Ciência.

Por fim, indicamos que a formação continuada é importante no viés epistemológico, além de ser constitutiva de cada uma das professoras, é uma oportunidade para que o mesmo olhe com outros sentidos e outras perspectivas o modo de compreender a Ciência na Educação Infantil, como uma linguagem que precisa ser ensinada na escola por meio de um ensino investigativo que pode ser realizado de diferentes formas.

\section{REFERÊNCIAS}

ARCE, Alessandra; SILVA, Debora A. S. M. da; VAROTTO, Michele. Ensinando ciências na educação infantil. Campinas SP: Alínea, 2011.

BRASIL, Ministério da Educação. Secretaria de Educação Básica. Diretrizes curriculares nacionais para a educação infantil / Secretaria de Educação Básica. - Brasília: MEC, SEB, 2010

BRASIL. Base Nacional Comum Curricular: Educação Infantil e Ensino Fundamental. Brasília: MEC/Secretaria de Educação Básica, 2017.

CARVALHO, Anna Maria Pessoa de; PÉREZ, Daniel Gil. Formação de professores de ciências: tendências e inovações.10 ed. São Paulo: Cortez, 2011.

CHALMERS, Alan. F. O que é ciência, afinal? São Paulo: Brasiliense, 1993. 
FIORETTI, Elena Campo. Desafios e possibilidades para a formação continuada de professores de crianças de 4 e 5 anos para a literacia científica no Município de Amajari, Roraima. Tese (Doutorado em Educação de Ciências e Tecnologia) - Programa de Pós-Graduação em Educação, da Faculdade de Ciências e Tecnologia "Júlio de Mesquita Filho", Universidade Estadual Paulista (Unesp), Faculdade de Ciências e Tecnologia, Presidente Prudente, 2018.

HAI, Alessandra Arce; SILVA, Debora. A. S. M; VAROTTO, Michele.; MIGUEL, Carolina Costa. Ensinando Ciências na Educação Infantil. 2 ed. Campinas, SP: Editora Alínea, 2020.

HARRES, João Batista Siqueira. Uma Revisão de Pesquisas nas Concepções de Professores sobre a Natureza da Ciência e suas implicações para o Ensino. Investigações em Ensino de Ciências - V4(3), pp. 197-211, 1999.

MOURA, Breno Arsioli. O que é natureza da Ciência e qual sua relação com a história e filosofia da Ciência. Revista Brasileira de História da Ciência, v. 7, n. 1, p. 32-46, 2014.

LÜDKE, Menga; ANDRÉ, Marli E. D. A. Pesquisa em educação: Abordagens Qualitativas, São Paulo: EPU,1986.

MACHADO, Andreia de Bem. Concepções de ciência entre professores das séries iniciais do ensino fundamental em Florianópolis, SC e suas relações com o ensino de ciências, 2007.

MORAES, Roque.; GALIAZZI, Maria do Carmo. Análise textual discursiva: processo reconstrutivo de múltiplas faces. In Ciência \& Educação, v. 12, n. 1, p. 117-128, 2006.

MORAES, Roque.; GALIAZZI, Maria do Carmo. Análise textual discursiva. 2. ed. Ijuí: Ed. Unijuí, 2011.

PRAIA. João.; CACHAPUZ, Antônio; GIL-PÉREZ, Daniel. A Hipótese E A Experiência Científica Em Educação Em Ciência: Contributos Para Uma Reorientação Epistemológica. In Ciência \& Educação, v. 8, n. 2, p. 253-262, 2002.

UJIIE, Nájela Tavares. Formação continuada de professores da educação infantil num enfoque CTS. Tese (Doutorado em Ensino de Ciência e Tecnologia) - Programa de Pós-Graduação em Ensino de Ciência e Tecnologia, Universidade Tecnológica Federal do Paraná, Ponta Grossa, 2020.

VYGOTSKY, Lev Semenovich. Pensamento e Linguagem. São Paulo: Martins Fontes, 1989.

VIGOTSKI, Lev Semenovich. Pensamento e Linguagem. Tradução Jeferson Luiz Camargo, revisão técnica José Cipolla Neto. São Paulo: Martins Fontes, 135 p, 1993.

VIGOTSKI, Lev Semenovich. Pensamento e Linguagem. São Paulo: Martins Fontes, 2009. ZABALA, Antoni. A prática educativa: como ensinar. Porto Alegre: Artmed, 1998.

Submissão: 15/03/2021

Aceito: 22/06/2021 